\title{
Electronegative low density lipoprotein subform is increased in patients with short-duration IDDM and is closely related to glycaemic control
}

\author{
J .L. Sánchez-Q uesada ${ }^{1}$, A . Pérez ${ }^{2}$, A . C aixàs ${ }^{2}$, J . O rdónmez-L lanos $^{1,3}$, G . C arreras ${ }^{2}$, A . Payés ${ }^{1}$, F. G onzález-Sastre ${ }^{1,3}$, \\ A . de L eiva $^{2}$ \\ ${ }^{1}$ D epartment of B iochemistry, H ospital de la Santa Creu i Sant Pau, B arcelona, Spain \\ ${ }^{2} \mathrm{D}$ epartment of E ndocrinology and N utrition, H ospital de la Santa Creu i Sant Pau, B arcelona, Spain \\ ${ }^{3} \mathrm{D}$ epartment of B iochemistry and M olecular B iology, U niversitat A utónoma de B arcelona, Spain
}

Summary We evaluated the effect of improving glycaemic control with intensive insulin therapy on LDL susceptibility to oxidation, electronegative LDL proportion, and LDL subfraction phenotype in a group of 25 patients with short-duration insulin-dependent diabetes mellitus (ID D M ); 25 matched healthy control subjects were also studied. LD L susceptibility to oxidation was measured by continuous monitoring of conjugated diene formation. E lectronegative LDL was isolated by anion exchange chromatography, and quantified as percentage of total $L D L$. Six LDL subfractions were isolated by density gradient ultracentrifugation and phenotype $\mathrm{A}$ or $\mathrm{B}$ classified as the quotient (LDL1-LDL3)/(LDL4LDL 6). Compared to the control group, IDDM subjects with poor glycaemic control showed higher electronegative $L D L \quad(19.03 \pm 10.09$ vs $9.59 \pm 2.98 \%$, $p<0.001)$, similar LDL subfraction phenotype and lower susceptibility to oxidation (lag phase $45.6 \pm 8.8$ vs $41.2 \pm 4.7 \mathrm{~min}, p<0.05)$. A fter three months of intensive insulin therapy, $\mathrm{HbA}_{1 \mathrm{c}}$ decreased from $10.88 \pm 2.43$ to $5.69 \pm 1.54 \% \quad(p<0.001)$, and electronegative $L D L$ to $13.84 \pm 5.15 \%$ $(p<0.05)$. No changes in LDL susceptibility to oxidation or LDL subfraction phenotype were observed. Electronegative LDL appeared significantly correlated to $\mathrm{HbA}_{1 \mathrm{c}}$ and fructosamine $(\mathrm{p}<0.01$ and $p<0.001$ ) only in poorly controlled IDDM patients. These findings suggest that high electronegative LDL in IDDM subjects is related to the degree of glycaemic control, and could therefore be due to LDL glycation rather than to $L D L$ oxidation or changes in LDL subfraction phenotype. [Diabetologia (1996) 39: 1469-1476]

Keywords Insulin-dependent diabetes mellitus, intensive insulin therapy, glycaemic control, electronegative $L D L, L D L$ subfraction phenotype, LDL oxidation.
A therosclerosis is the major cause of death in the diabetic population. $\mathrm{H}$ yperglycaemia per se is an independent risk factor for the development of cardiovascular disease, in spite of the coexistence of other

R eceived: 20 D ecember 1995 and in final revised form: 19June 1996

Corresponding author: Dr. A . Pérez Pérez, Servei de E ndocrinologia i Nutrición, H ospital de la Santa Creu i Sant Pau, C/. A ntoni M aría Claret 167, E-B arcelona 08025, Spain

A bbreviations: IIT, Intensive insulin therapy; LDL(-), electronegative LDL subform; FPLC, fast protein liquid chromatography; PBS, phosphate buffered saline; ID D M, insulin-dependent diabetes mellitus; NID D M , non-insulin-dependent diabetes mellitus. known risk factors, such as hyperlipidaemia and hypertension [1,2]. E levated concentrations of low density lipoproteins ( $L D L)$ are also a major risk factor in the general population $[3,4]$. H owever, LD L levels are usually normal in both insulin-dependent diabetes mellitus (ID D M) and non-insulin-dependent diabetes (NIDD M ) $[2,5]$.

It has been postulated that the increased cardiovascular risk for diabetic patients could be related, among other factors, to LDL qualitative modifications such as oxidation and glycation. These modifications impair LDL cellular catabolism, leading to loss of affinity for LDL receptors in fibroblasts, increased accumulation of cholesteryl esters in macrophages, and immunological responses $[6,7]$. In 
addition, it has been reported that glycation and oxidation processes are closely related, and potentially accelerated by each other [8]. Some authors have measured plasma lipid peroxides in human diabetes $[9,10]$ and proposed that increased lipid peroxides are usually related to underlying atherosclerosis. A higher autoantibody titre against oxidized and glycated LDL has recently been reported in NIDDM patients when compared to control subjects [11]. Several groups have reported increased susceptibility to oxidation of LDL isolated from diabetic patients [12-19], although other authors disagree [20, 21]. In particular, studies carried out in IDDM subjects that showed higher susceptibility to oxidation [15-18] have been performed in patients with diabetes of more than 10 years duration.

Other qualitative LDL changes, such as prevalence of small, dense LDL particles have been described in patients with enhanced cardiovascular risk [22], including both IDDM and NIDDM [23-25]. The predominance of small, dense $L D L$ subfractions (named phenotype B) is associated with relatively increased concentrations of plasma triglyceride, which is usually present in poorly controlled diabetic subjects. Increased atherogenicity of small LDL may be related, among other factors, to its increased susceptibility to oxidation when compared to that of large, buoyant LDL particles [26].

On the other hand, the presence of a plasma circulating electronegative $L D L$ form (named $L^{-} L^{-}$) has been described, and suggested that it was the result of a peroxidative process. These particles had a higher content of lipoperoxides, cholesterol oxides, lower content of $\alpha$-tocopherol, and higher electrophoretic motility [27-29]. In addition, loss of affinity of these particles for the LD L receptor in fibroblasts has also been observed [27]. 0 ther authors [30] have also reported the presence of an oxidation-labile LDL subfraction in plasma, with negative electrical charge. However, the oxidative origin of the electronegative LDL has recently been questioned [31]. The origin and relevance of this circulating modified LDL are not clear, but its increased plasma concentration has been related to high atherosclerosis risk [32].

A s far as we know, the effect of improved glycaemic control on the LDL subfraction distribution has only been evaluated in very short-term studies (2 weeks) $[23,24]$, and no data are available on the LDL susceptibility to oxidation and the proportion of electronegative LDL. In this investigation, we have evaluated the effect of 3 months of intensive insulin therapy (IIT) achieving blood glucose optimization on the aforementioned parameters. For this purpose, we studied a group of patients with short-duration IDDM, without chronic complications in order to avoid pathogenic factors other than hyperglycaemia.

\section{Subjects and methods}

Patients. We included 25 patients ( 20 males and 5 females) with IDDM in the study. They were recruited from the diabetes clinic on the basis of poor glycaemic control [glycated haemoglobin $\left(\mathrm{HbA}_{1 \mathrm{c}}\right)>8 \%$, non-ketoacidosis]. IDDM was defined according to the National Diabetes Data Group criteria [33]. A II patients older than 30 years showed positivity for islet-cell antibodies. Mean age was $28.1 \pm 10.3$ years (range: 14-47), and mean body mass index (BMI) $21.6 \pm 3.15 \mathrm{~kg} / \mathrm{m}^{2}$ (range: 17.2-29.8). K nown diabetes duration range was $0-20$ months, with 19 of 25 being new-onset diabetic patients, not previously treated. None had chronic diabetic complications and $32 \%$ were smokers.

We also recruited 25 age-sex matched healthy control subjects ( 20 males and 5 females) from the hospital staff as control group. Their mean age was $28.7 \pm 10.0$ years (range:16-49), B M I $22.8 \pm 2.95 \mathrm{~kg} / \mathrm{m}^{2}$ (range:17.8-29.4) and $28 \%$ were smokers. B M I had remained stable for at least 1 year previous to their inclusion in the study. N one of the patients or control subjects were taking drugs (other than insulin) or vitamins, or had any disease known to influence lipoprotein metabolism.

A II patients were included in an intensive insulin therapy programme with regular insulin before main meals, and intermediate insulin before dinner or at bedtime. Patients were instructed observe an isocaloric diet, providing 50-55\% carbohydrate and $30-35 \%$ fat. A II of them were given a specific diabetes education programme and visited the outpatient unit every 2-4 weeks. A ssessment was carried out at baseline and after 3 months of intensive insulin therapy.

The study was approved by the hospital ethics committee, and all patients and control subjects gave their informed consent.

B lood glucose analysis. G lucose was determined by a standarized automated method adapted to a H itachi 747 autoanalyzer ( $\mathrm{H}$ itachi, $\mathrm{H}$ itachi-Boehringher $\mathrm{M}$ annheim, M annheim, Germany). Fructosamine was determined by a standard colourimetric method (Boehringer M annheim, M annheim, Germany) (normal range: $205-285 \mu \mathrm{mol} / \mathrm{l})$. $\mathrm{H} \mathrm{bA}_{1 \mathrm{c}}$ was determined by H PL C [H i-A utoA 1 c H A -8121 A nalyzer (D ic-K ioto, K ioto, Japan) ], normal range: $3.7-5.5 \%$.

L ipid analysis. Lipoproteins were quantified by the combined ultracentrifugation-precipitation method, as recommended by the L ipid Research Clinics L aboratory [34]. Cholesterol and triglyceride concentrations from EDTA -plasma and lipoprotein fractions were determined by enzymatic methods ( $B$ oehringer $\mathrm{M}$ annheim) adapted to an R A - X T autoanalyzer (B ayer, L everkusen, Germany). LDL composition was calculated from plasma isolated LDL (densities 1025-1050 g/l). Total and free cholesterol, triglyceride, phospholipid (enzymatic method, Wako, Wako Chemicals $\mathrm{GmbH}$, Neuss, Germany) and protein [35] content were expressed as percentage of total LDL mass.

\section{D L oxidation studies}

1. I solation of native $L D L$ particles. Plasma aliquots from venous blood drawn in $7.5 \%$ E DTA -containing vacutainer tubes, were isolated by centrifugation at $1500 \mathrm{~g}$ for $15 \mathrm{~min}$ at $4^{\circ} \mathrm{C}$, and stored at $-80^{\circ} \mathrm{C}$ until processed (before 16 weeks). A fter thawing plasma, native LD L (density range 1025-1050 g/l) was isolated by sequential ultracentrifugation [36]. In order to avoid oxidative modification of lipoproteins, ultracentrifugation was 
performed at $4^{\circ} \mathrm{C}$ with $\mathrm{KBr}$ solutions containing $1 \mathrm{mmol} / \mathrm{l}$ EDTA. LDL was dialysed extensively against degassed $10 \mathrm{mmol} / \mathrm{l}$ Tris- $\mathrm{HCl}$ buffer $\mathrm{pH} \mathrm{7.4,} \mathrm{containing} 1 \mathrm{mmol} / \mathrm{l}$ EDTA, and stored at $4^{\circ} \mathrm{C}$ in the dark.

2. Identification of the electronegative $L D L$ subform. Electronegative subform of $L D L$ was isolated from total $L D L$ by chromatography in an anion exchange column (M ono Q 5/5) with a Fast Protein Liquid Chromatography (FPLC) system (Pharmacia, U ppsala, Sweden), as described [37, 38], with additional minor modifications in order to shorten the duration of $\mathrm{NaCl}$ gradient process. Briefly, LDL was eluted at $1 \mathrm{ml} / \mathrm{min}$ for $10 \mathrm{~min}$ by a linear gradient of $0-0.1 \mathrm{~mol} / \mathrm{NaCl}$, followed by a multistep gradient procedure: $10-18 \mathrm{~min} 0.2 \mathrm{~mol} / \mathrm{l} \mathrm{NaCl}$, $18-24 \min 0.3 \mathrm{~mol} / \mathrm{NaCl}, 24-29 \mathrm{~min} 1 \mathrm{~mol} / \mathrm{l} \mathrm{NaCl}$, and $29-$ $35 \mathrm{~min} 0 \mathrm{~mol} / \mathrm{l} \mathrm{NaCl}$. Two LDL forms, a major form named $L D L^{(+)}$(elution at $0.2 \mathrm{~mol} / / \mathrm{NaCl}$ ), and a minor form named $\mathrm{LDL}^{(-)}$(elution at $0.3 \mathrm{~mol} / \mathrm{l} \mathrm{NaCl}$ ), differing in their electrical charges, were identified at $280 \mathrm{~nm}$ and their relative proportion quantified by peak integration.

3. "In vitro" $L D L$ susceptibility to oxidation. $L D L$ was dialysed against phosphate buffer saline (PBS) pH 7.4 by gel filtration chromatography in a G-25 Sephadex column (Pharmacia), diluted to a concentration of $50 \mathrm{mg}$ of protein/l, and incubated with $2.5 \mathrm{umol} / \mathrm{I} \mathrm{CuSO}_{4}$ at $30^{\circ} \mathrm{C}$. Conjugated diene formation of an aliquot of $L D L$ was continuously monitored at $234 \mathrm{~nm}$ for $3 \mathrm{~h}$, according to E sterbauer et al. [39], although using a different $\mathrm{Cu}++$ /protein ratio (50 vs 16.6), as described above, in a $B$ iochrom 4060 spectrophotometer equipped with a seven-position cell changer (Pharmacia L K B ). Lag phase time (expressed as $\mathrm{min}$ ) and diene rate formation (maximal curve slope expressed as $\Delta \mathrm{abs} / \mathrm{min}$ ) were measured. Pre- and post-treatment samplescorresponding to the same I D D M patient and a sample from a control subject were assayed in the same batch. In our laboratory we have obtained an intra-assay imprecision of $2.88 \%$ for the lag phase time and $3.08 \%$ for the diene rate formation. O ur inter-assay imprecision was $6.00 \%$ for the lag phase time and $14.7 \%$ for the diene rate formation. In order to study the viability of freezing plasma we studied 12 samples before and after 3 months of freezing at $-80^{\circ} \mathrm{C}$, and no statistical significant differences were found (fresh plasma lag phase time $45.4 \pm 5.0 \mathrm{~min}$; frozen plasma lag phase time $45.6 \pm 5.9 \mathrm{~min}$ ).

LDL subfraction distribution. $L D L$ subfractions were isolated from aliquots of frozen plasma-E DTA at $-80^{\circ} \mathrm{C}$ according to the method of Griffin et al. [40] with some modifications $\left(37000 \mathrm{rev} / \mathrm{min}\right.$ during $20 \mathrm{~h}$ at $20^{\circ} \mathrm{C}$ ). Subfraction isolation also differed from this method. B riefly, six $L D L$ subfractions LD L 1 (density range 1.020-1.026 $\mathrm{g} / \mathrm{ml}$ ), L D L 2 (1.026-1.030), LDL 3 (1.030-1.036), LDL 4 (1.036-1.043), LDL5 (1.043$1.051)$ and LDL 6 (1.051-1.056), were isolated by aspiration of $0.8 \mathrm{ml}$ aliquots. I $\mathrm{n}$ order to assess the lack of mixture of the different subfractions, potassium concentration in each aliquot was determined, and the corresponding density calculated. Cholesterol, triglyceride, phospholipid and protein content of each subfraction was determined as described above. LDL subfraction mass was calculated by the sum of each constituent. Results were expressed as the percent contribution of each subfraction to the total $L D L$ mass, and the ratio $[(L D L 1+L D L 2+L D L 3) /(L D L 4+L D L 5+L D L 6)]$ was calculated. A ccording to our previous results [38], we classified LDL subfraction phenotype A when the ratio exceeded 1.8, B when it was below 1.1 , and $A B$ when it ranged from 1.1 to 1.8 . Thus, we considered small dense LD L particles when predominant density was higher than the cut-off value of $1.036 \mathrm{~g} / \mathrm{ml}$, similar to that reported by other authors [41-43]. Pre- and post-treatment samples corresponding to the same ID D M patient and the sample corresponding to one control subject were assayed in the same batch. R esults obtained in our laboratory showed that freezing only modified the subfraction ratio by $8.7 \%$ without modifying phenotype assignation.

Statistical methods. Statistical differences between both periods of glycaemic control for ID D M patients were assessed by using paired Student's t-test when the variables were normally distributed, and non-parametric test (Wilcoxon t-test) for variables without normal distribution. U npaired Student's t-test and $\mathrm{M}$ ann-Whitney $\mathrm{U}$-test were used to compare the diabetic patients with the control group. Fisher's exact probability test evaluated differences in LDL phenotype distribution (phenotype $A$ vs phenotype $A B+B$ ). A ssociation between variables was tested by linear correlation ( $r$ ). In all cases, a probability (p) less than 0.05 was considered as statistically significant. All data are expressed as mean \pm SD.

\section{Results}

Table 1 shows clinical characteristics, glycaemic control parameters and plasma lipid levels of diabetic and control subjects. Diabetic patients during poor glycaemic control (before IIT) presented an abnormal lipoprotein profile evidenced by higher plasma levels of triglyceride, VLDL cholesterol ( $C V L D L$ ) and LDL cholesterol ( $C L D L$ ), and lower HDL cholesterol (cHDL) concentration than the control group. Table 2 shows the LD L susceptibility to oxidation, $L D L^{(-)}$proportion and $L D L$ subfraction ratio for control group and diabetic patients before and after blood glucose optimization with IIT. The percentage of $L D L^{(-)}$in poorly controlled IDDM was significatively higher than in the control group $(19.0 \pm 10.1$ vs $9.59 \pm 2.98 \%, p<0.001)$. However, LDL from poorly controlled IDDM patients showed a significant $(p<0.05)$ enhancement on the resistance to oxidative modification, when compared with control subjects, as indicated by the longer lag phase time of conjugated diene formation ( $45.6 \pm 8.81$ vs $41.2 \pm 4.71 \mathrm{~min}$ ). The rate of conjugated diene formation did not differ between IDDM and control groups. In addition, LDL susceptibility to oxidation and the percentage of $L D L^{(-)}$did not differ between smokers and non-smokers and were not significant in either IDD M or control subjects (data not shown). Concerning LDL composition (Table 3), LDL particles from IDDM patients before IIT showed a higher percentage of triglyceride $(7.68 \pm 4.09$ vs $5.65 \pm 1.11 \%, p<0.001$ ) and a lower percentage of polar lipids (free cholesterol: $12.8 \pm 1.45$ vs $14.6 \pm 1.32 \% \quad p<0.001$; phospholipid: $31.3 \pm 1.38$ vs $32.2 \pm 0.59 \%, p<0.01$, respectively) than control subjects. With regard to $L D L$ subfraction distribution phenotype, no differences ( $p=0.18$ ) were observed between the diabetic patients and non-diabetic subjects (Fig. 1), with clear predominance of phenotype A in both groups ( 84 and $96 \%$, respectively). Three 
Table 1. Clinical characteristics and parameters of glycaemic control and lipoprotein profile of control subjects and ID D M patients before and after intensive insulin therapy (IIT)

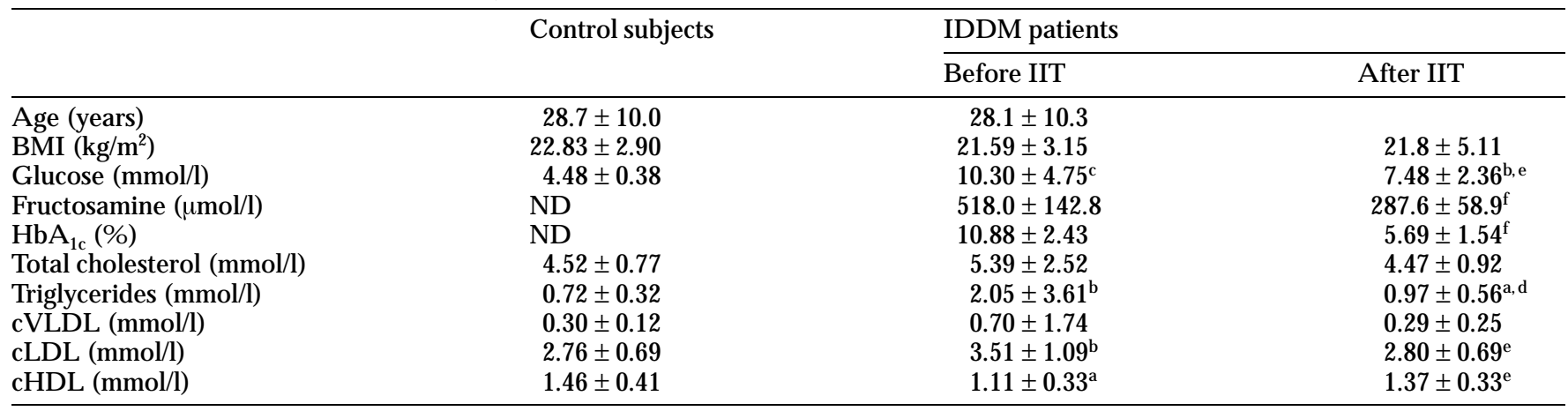

$\mathrm{D}$ ata are mean $\pm \mathrm{SD}$

ND, not determined; ${ }^{a} p<0.05 ;{ }^{b} p<0.01 ;{ }^{c} p<0.001$ vs control subjects; ${ }^{d} p<0.05 ;{ }^{e} p<0.01 ;{ }^{f} p<0.001$ vs IDDM before IIT

Table 2. LDL susceptibility to oxidation (lag phase time and conjugated diene rate formation) electronegative LDL proportion $\left(L D L^{(-)}\right)$, and $L D L$ subfraction ratio [ ( $\left.\left.L D L 1+L D L 2+L D L 3\right) /(L D L 4+L D L 5+L D L 6)\right]$ of IDDM patients before and after IIT, and control subjects

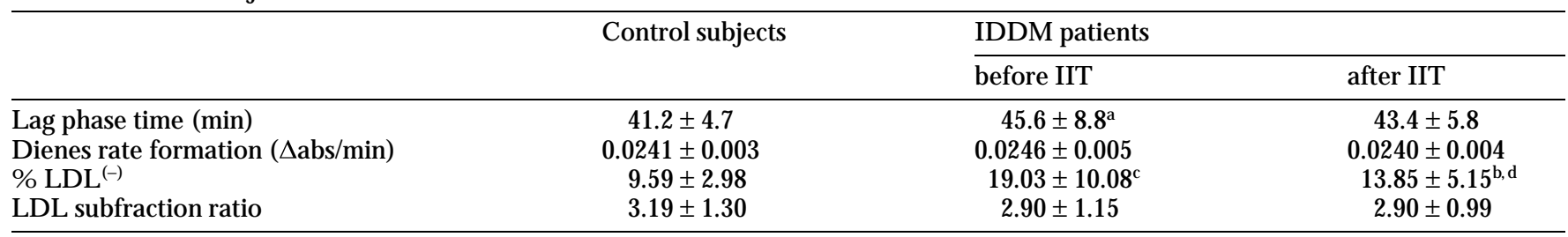

D ata are mean \pm SD

${ }^{a} p<0.05 ;{ }^{b} p<0.01 ;{ }^{c} p<0.001$ vs control subjects; ${ }^{d} p<0.05$ vs ID D M before IIT

Table 3. LD L composition (expressed as percentage of LDL mass) of control subjects and ID D M patients before and after intensive insulin therapy (IIT)

\begin{tabular}{lccc}
\hline & Control subjects & ID D M patients & after IIT \\
\cline { 3 - 4 } & & before IIT & $45.04 \pm 2.21^{\mathrm{a}}$ \\
\hline Total cholesterol & $46.34 \pm 1.39$ & $45.72 \pm 3.88$ & $31.94 \pm 2.76$ \\
E sterified cholesterol & $31.75 \pm 2.13$ & $32.82 \pm 3.69$ & $13.09 \pm 1.63^{c}$ \\
Free cholesterol & $14.59 \pm 1.32$ & $12.89 \pm 1.45^{c}$ & $7.70 \pm 2.35^{c}$ \\
Triglyceride & $5.65 \pm 1.11$ & $7.68 \pm 4.09^{c}$ & $32.23 \pm 1.74^{\mathrm{d}}$ \\
Phospholipid & $32.17 \pm 0.59$ & $31.31 \pm 1.38^{\mathrm{b}}$ & $15.01 \pm 2.04$ \\
Protein & $15.80 \pm 0.91$ & $15.32 \pm 1.51$ & \\
\hline
\end{tabular}

Data are mean \pm SD

${ }^{a} p<0.05 ;{ }^{b} p<0.01 ;{ }^{c} p<0.001$ vs control subjetcs; ${ }^{d} p<0.005$ vs ID D M before IIT

diabetic patients and one control subject displayed phenotype A B. Only one diabetic subject with high plasma cholesterol and triglyceride concentrations showed phenotype $B$.

A fter 3 months of IIT, glycaemic control improved significantly (Table 1 ). This improvement of glycaemic control was accompanied by normalization of lipoprotein concentrations, which became similar to those of the control subjects. B riefly, total plasma cholesterol decreased by $17 \%$, triglyceride $53 \%$ $(p<0.05)$, cVLDL $59 \%$, and $C L D L 20 \%(p<0.01)$, whereas CHDL increased by $33 \%(p<0.01)$. A II of these changes were greater than those attributed to intraindividual biological variation of these lipidic constituents regardless of statistical significance [44]. A fter improvement of glycaemic control with IIT, the percentage of $L L^{(-)}$also decreased significantly (from $19.0 \pm 10.1 \%$ to $13.8 \pm 5.15 \%, p<0.05$ ), but still remained higher $(p<0.01)$ than the control group. Figure 2 shows a representative chromatogram of the LDL elution profile obtained from one IDDM patient before and after IIT. In contrast, LDL susceptibility to oxidation (expressed as lag phase time and rate of conjugated diene formation) did not change (Table 2), although significant differences compared to the control group disappeared. LDL composition (Table 3) did not change after IIT, except for a trend towards normalization of the 


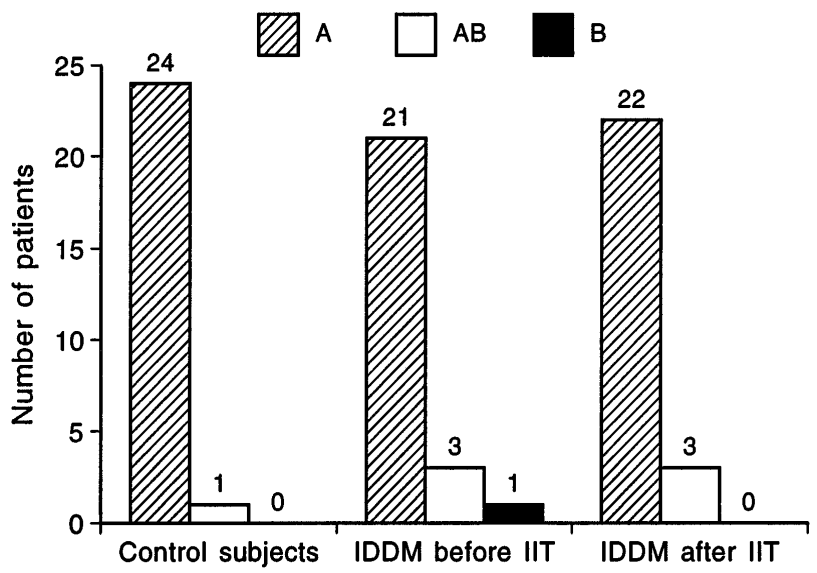

Fig. 1 LDL subfraction phenotype of control subjects and IDDM patients before and after intensive insulin therapy (IIT). N o statistical differences were observed $(p=0.18$, Fisher's exact probability test). The LDL subfraction pattern was classified as $A$ when the subfraction ratio $[(L D L 1+L D L 2+L D L 3) /(L D L 4+L D L 5+L D L 6)]$ exceeded 1.8, as $B$ when the ratio was below 1.1, and as $A B$ when the ratio was between 1.1 and 1.8

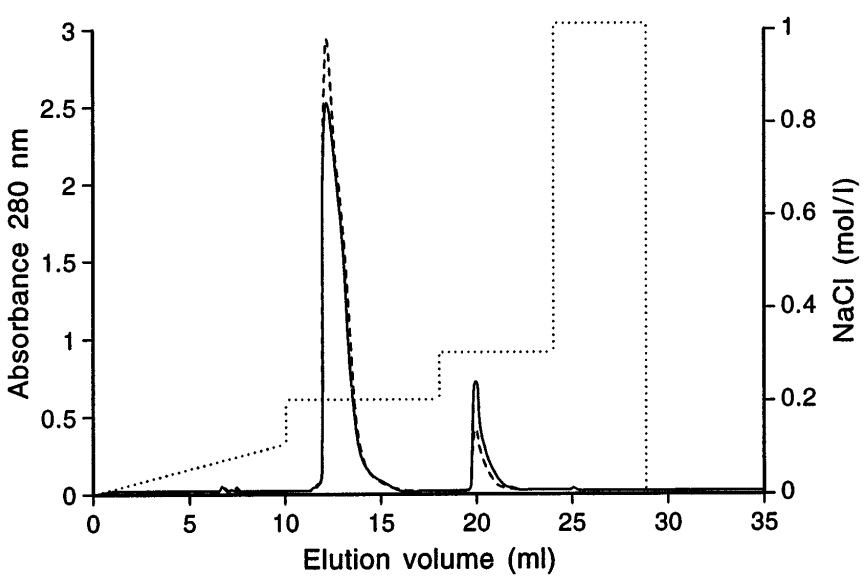

Fig. 2 Representative chromatographic profile of $L D L$ from an IDDM patient before IIT (continuous line) and after IIT (dashed line). $\mathrm{NaCl}$ gradient (right axis, dotted line) was formed with buffer A ( $10 \mathrm{mmol} / \mathrm{l}$ Tris- $\mathrm{HCl}, 1 \mathrm{mmol} / \mathrm{IEDTA}$, $\mathrm{pH}$ 7.4) and buffer $\mathrm{B}(10 \mathrm{mmol} / \mathrm{l}$ Tris- $\mathrm{HCl}, 1 \mathrm{mmol} / / \mathrm{EDTA}$, $1 \mathrm{~mol} / \mathrm{l} \mathrm{NaCl}, \mathrm{pH}$ 7.4), as indicated in Materials and $\mathrm{M}$ ethods. M ost of the LDL ( $L D L+$ ) eluted with $0.2 \mathrm{~mol} / \mathrm{l} \mathrm{NaCl}$ between 12-15 ml. LD L ${ }^{(-)}$eluted with $0.3 \mathrm{~mol} / / \mathrm{N} \mathrm{aCl}$ between $19-21 \mathrm{ml}$

percentage of phospholipids (from $31.3 \pm 1.38$ to $32.2 \pm 1.74 \%, p<0.005)$. L D L subfraction phenotype also remained unchanged for all diabetic patients showing phenotype A or A B. However, following the marked improvement in glycaemic control and the dramatic diminution of plasma cholesterol (from 16.2 to $4.19 \mathrm{mmol} / \mathrm{l}$ ) and triglyceride (from 18.4 to $0.69 \mathrm{mmol} / \mathrm{l}$ ), the single patient with phenotype B changed it to phenotype A.

The proportion of $L D L^{(-)}$in IDDM patients before IIT, positively correlated with $\mathrm{HbA}_{1 \mathrm{c}}(r=0.535$, $p<0.01)$ and fructosamine levels $(r=0.639$, $\mathrm{p}<0.0005)$, as well as with total plasma triglyceride ( $r=0.657, p<0.0005)$, percentage of $L D L$ triglyceride $(r=0.599, p<0.001)$ and LDL protein $(r=0.571$, $p<0.001)$, and negatively correlated with that of LDL cholesterol $(r=-0.761, p<0.0005)$ and $L D L$ phospholipid $(r=-0.421, p<0.05)$. A II these statistically significant associations disappeared after IIT. On the other hand, lag phase time, in poorly controlled IDDM patients positively correlated with $\mathrm{HbA}_{1 \mathrm{c}}(r=0.401, \mathrm{p}<0.05)$ and fructosamine levels $(r=0.545, p<0.01)$. Concerning LDL composition, lag phase time showed a positive correlation with the percentage of $L D L$ triglyceride $(r=0.626$, $p<0.0005)$ and a negative one with that of LD L cholesterol $(r=-0.559, p<0.01)$ and $L D L$ phospholipid $(r=-0.412, p<0.05)$. A fter optimization of glycaemic control, all significant correlations disappeared. In addition, the percentage of $L L^{(-)}$and lag phase time were highly correlated $(r=0.519, p<0.005)$ in diabetic patients before IIT, but this strong relationship disappeared after the marked improvement of $\mathrm{HbA}_{1 c^{\circ}}$ In the control group, the single significant correlation observed between the investigated parameters was a positive correlation between total plasma triglycerides and $\mathrm{LDL}^{(-)}(r=0.412, p<0.05)$.

\section{Discussion}

Considerable effort has been focused on identifying the leading factors for diabetic vascular complications. Q ualitative modification of LD L is strongly implicated as a major factor in the current hypothesis of the pathogenesis of atherosclerosis [6]. Since increased atherosclerotic risk in the diabetic population is not always associated with increased lipoprotein concentration, and qualitative modifications of $L D L$ particles play a central role in the development of arteriosclerotic lesions, we have evaluated the effect of marked improved glycaemic control by IIT on LDL susceptibility to oxidation, $\operatorname{LDL}^{(-)}$proportion, and LDL subfraction phenotype in a group of patients with IDDM of short-duration.

In accordance with others [45], quantitative abnormalities of lipoprotein profile found in poorly controlled IDDM were reversed by marked improvement of glycaemic control. All the variations observed in the lipoprotein profile (including those not showing statistical differences), were above the intraindividual variations described for reference subjects [44]. Concerning qualitative alterations, two findings were found to be of interest: decreased L D L susceptibility to oxidation and higher proportion of $L L^{(-)}$in IDDM patients during the stage of poor glycaemic control.

R egarding LDL susceptibility to oxidation, previously reported results by other authors are controversial. In most cases, LDL from NIDDM patients is 
more susceptible to oxidation [12-14, 19, 46], probably reflecting the well-known diminished resistance to oxidation of small LDL particles [26] which is increased in these patients [25]. R egarding IDDM subjects, most studies [15-18] were performed in patients with diabetes of long duration (10 years or more) and displayed increased LDL susceptibility to oxidation when compared to control subjects. Those studies describing decreased [20] or no difference [21, 47] in LDL susceptibility to oxidation between IDDM and control subjects, did not report the duration of the disease. 0 ur results showing decreased susceptibility to oxidation of LD L from IDD M patients when compared to control subjects, were not due to differences in LDL subfraction phenotype. D iscrepancies between the present results and those showing an increased susceptibility to oxidation of LDL in IDDM, could be attributed to differences in the recruited groups and also in biochemical procedures. In this investigation, the diabetic population mainly comprised new onset patients, while in other studies [1518], diabetes had lasted for at least 10 years. L onger diabetes duration could contribute to increasing the LDL susceptibility to oxidation. In this regard it has been reported $[10,48]$ that increased plasma lipid peroxidation in diabetes may not reflect the consequences of high blood glucose, but may be related to underlying complications, in particular atherosclerosis developed during long-duration diabetes. In these circumstances, structural proteins from the vascular wall become modified by advanced glycation endproducts, resulting in enhanced trapping of lipoproteins, which could contribute to prolong their halflife in plasma [49] and, thus, facilitate atherogenic modifications. This hypothesis is supported by the recent findings of Walzem et al. [50] who observed a relationship between the susceptibility to oxidation of lipoproteins and their permanence in the bloodstream. As the present study was conducted in IDDM of short-duration without chronic complications, it might be assumed that LDL susceptibility to oxidation was not affected by underlying atherosclerosis. On the other hand, in vitro glycated LDL has been described as more resistant to oxidative modification than native LDL [13]. This may contribute to explain the longer lag phase time observed in our study in IDDM patients with respect to control subjets. It could be hypothesized that LD L glycation in patients with short-duration IDDM, in the absence of chronic complications, would make LDL particles more resistant to oxidative stress. Further studies should be developed using in vivo glycated LD L isolated from both short and long-duration IDDM subjects, in order to clarify these findings.

For several years, different authors have described the presence of a minor plasma circulating $L D L$ with increased negative charge, which has been described as a mildly oxidized particle. I ts role in the development of atherosclerosis remains unclear, although it has some atherogenic characteristics [27$30,37,38]$, and has been related to increased atherosclerosis risk [32]. O ur group previously described an increase of $L D L^{(-)}$proportion in trained subjects after heavy aerobic exercise [38], possibly as a consequence of increased of free radical production during exercise, in association to enhanced susceptibility to oxidation of the LDL. In the present work, some distinctive features between poorly controlled IDDM patients and the control group or IDDM patients after IIT were observed. First, the strikingly high $\mathrm{LD} \mathrm{L}^{(-)}$proportion positively correlated with parameters of glycaemic control, plasma triglyceride and lag phase time. Secondly, the lag phase time was longer and positively correlated with parameters of glycaemic control. Furthermore, significant differences on lag phase time between poorly controlled IDDM and the control group disappeared after IIT. Finally, the $L D L^{(-)}$proportion diminished after IIT, and all statistically significant correlations among parameters disappeared. These findings suggest that possibly the increased proportion of LDL ${ }^{(-)}$in poorly controlled ID D M patients could be a consequence of glycation rather than a consequence of lipoperoxidation. Supporting these data, we have observed that in vitro glycated LDL by the method of Steinbrecher and Witzum [51] elutes at the same ionic strength ( $0.3 \mathrm{~mol} / \mathrm{l} \mathrm{NaCl}$ ) than LDL ${ }^{(-)}$(unpublished observations), as other authors have described $[52,53]$. H owever, other modifications affecting LDL charge, as desialylation [54] cannot be discarded as relevant in diabetic patients. Further studies should be developed to elucidate the origin of the negative charge of $\mathrm{LD} \mathrm{L}^{(-)}$in diabetic subjects.

$O$ ne of the alterations in LDL composition confirmed in patients with poorly controlled IDDM, was the triglyceride enrichment $[23,55]$. LD L was also depleted of free cholesterol and phospholipid. A fter improving blood glucose control, only the phospholipid percentage of LDL particles increased towards normalization, but the other alterations persisted. The depletion in free cholesterol observed in the IDDM group contrasts with the increased resistance to oxidation of LDL particles, as free cholesterol has been suggested to act as a protective factor against free radical induced oxidation. However, other factors such as antioxidant vitamins and/or fatty acid composition modulate the response of $L D L$ to an oxidative stress [56]. Furthermore, these compositional modifications are probably too subtle to be reflected as a significant change on the LD L susceptibility to oxidation. The lack of complete normalization of lipoprotein compositional abnormalities even after improving glycaemic control, has already been described by other authors $[55,57]$ and it may be due to the non-complete normalization of glycaemic control achieved, or to the non-physiological 
portal/peripheral insulin levels obtained by subcutaneous administration [57].

In conclusion, high proportion of $L D L^{(-)}$subform and compositional abnormalities in LD L particles are present in poorly controlled patients with IDDM of short-duration, in the absence of chronic complications, and appear to be dependent on the degree of glycaemic control. N ear-normalization of glycaemic control improves these alterations, without changes in the LDL subfraction phenotype. Increased LDL ${ }^{(-)}$proportion might be a consequence of $L D L$ glycation rather than $L D L$ oxidation. Furthermore, the duration of diabetes seems to be of outstanding importance to evaluate qualitative characteristics of $L D L$, such as susceptibility to oxidation and/or subfraction phenotype. Future research should clarify the $L D L^{(-)}$origin, and whether it may play a pathogenic role in the development of atherosclerosis in diabetic patients.

A cknowledgements. This work was supported by grants from the Fondo de Investigación Sanitaria de la Seguridad Social (FISS-95/1252), from the Dirección General de Ciencia y Tecnología of the Ministerio de Educación y Ciencia (DGICY T SA F 93/0313), and from the Direcció $G$ eneral de R ecerca of the Generalitat de Catalunya (FI/942 102).

We are indebted to A gustina Castellví and R osa B onet for their helpful technical assistance.

\section{References}

1. Pyörälä K, Laakso M, U usitupa M (1987) Diabetes and atherosclerosis: an epidemiologic view. Diabetes Metab R ev 3: 463-524

2. A ssmann G, Schulte H (1988) The prospective cardiovascular M unster (PR O CA M ) study: Prevalence of hyperlipidemia in persons with hypertension and/or diabetes mellitus and the relationship to coronary heart disease. A m Heart J 116: 1713-1724

3. Brown M S, Goldstein J L (1976) Familial hypercholesterolemia: a genetic defect in the low density lipoprotein receptor. N Engl J M ed 294: 1386-1390

4. Castelli WP, Garrison RJ, Wilson PWF, A bbott R D, Kalousdian S, K annel WB (1986) Incidence of coronary heart disease and lipoprotein cholesterol: the Framingham H eart Study. JA M A 256: 2835-2838

5. The DCCT R esearch Group (1992) Lipid and lipoprotein levels in patients with insulin-dependent diabetes mellitus: the $D$ iabetes Control and Complications Trial (DCCT) experience. D iabetes Care 15: 886-894

6. Steinberg D, Parthasarathy S, Carew TE, Khoo JC, Witztum J L (1989) B eyond cholesterol. Modifications of low density lipoprotein that increase its atherogenicity. N E ngl J Med 320: 915-924

7. Lyons TJ, K lein R L, Baynes J W, Stevenson H C, L opes-V irella M S (1987) Stimulation of cholesteryl ester synthesis in human monocyte-derived macrophages by low density lipoproteins from type 1 (insulin-dependent) diabetic patients: The influence of non-enzymatic glycosylation of low density lipoprotein. D iabetologia 30: 916-923

8. Wolff SP, D ean RT (1987) Glucose autoxidation and protein modification: the potential role of autoxidative glycosylation in diabetes mellitus. B iochem J 245: 243-250
9. Sato $Y$, H otta N Sakamoto N, M atsuoka S, O hishi N, Yagi K (1979) Lipid peroxide level in plasma of diabetic patients. Biochem Med 21: 104-107

10. Stringer MD, Gorog PG, Freeman A, Kakkar V V (1989) Lipid peroxides and atherosclerosis. B M J 298: 281-284

11. B ellomo G, M aggi E, Poli M, A gosta FG, B ollati P, Finardi G (1995) A utoantibodies against oxidatively modified low density lipoproteins in NID D M. D iabetes 44: 60-66

12. B owie $A$, O wens $D$, Collins $P$, Johnson $A$, Tomkin $G H$ (1993) G lycosylated low density lipoprotein is more sensitive to oxidation: implications for the diabetic patient? A therosclerosis 102: 63-67

13. B abiy A V, G ebicki J M, Sullivan D R, Willey K (1992) Increased oxidizability of plasma lipoproteins in diabetic patients can be decreased by probucol therapy and is not due to glycation. B iochem Pharmacology 43: 995-1000

14. D imitriadis $E$, $G$ riffin $M$, O wens $D$, Johnson A, Collins $P$, Tomkin GH (1995) Oxidation of low density lipoprotein in NIDDM :its relationship to fatty acid composition. Diabetologia 38: 1300-1306

15. T sai E C, H irsch IB, B runzell J D, Chait A (1994) R educed plasma peroxyl radical trapping capacity and increased susceptibility of LD L to oxidation in poorly controlled IDDM. D iabetes 43: 1010-1014

16. B eaudeux J L, Guilauseau PJ, Peynet J et al. (1995) Enhanced susceptibility of low-density lipoprotein to in vitro oxidation in type 1 and type 2 diabetic patients. Clin Chim A cta 239: 131-141

17. Cominacini L, Garbin U, Pastorino A M et al. (1994) Increased susceptibility of $L D L$ to in vitro oxidation in patients with insulin-dependent and non-insulin-dependent diabetes mellitus. D iabetes $R$ es 26: 173-184

18. R abini R A, Fumelli P, G alassi R, D ousset $N$, Taus M, Ferretti $G, M$ azzanti $L$, Curatola $G$, Solèra $M L$, Valdiguié $P$ (1994) Increased susceptibility to lipid oxidation of low density lipoproteins and erythrocyte membranes from diabetic patients. M etabolism 43: 1470-1474

19. R eaven PD, Barnett J, H erold DA, E delman S (1995) E ffects of vitamin $E$ on susceptibility of low-denstity lipoprotein and low-density lipoprotein subfractions to oxidation and on protein glycation in NIDDM. Diabetes Care 18: 807-816

20. Taus $M$, Ferretti $G, C$ uratola $G$, D ousset $N$, Solèra $M L$, Valdiguié $P$ (1992) L ower susceptibility of low density lipoprotein to in vitro oxidation in diabetic patients. Biochem Int 28: 835-842

21. Gugliucci A, Menini T, Stahl A J (1994) Susceptibility to copper-enhanced autoxidation of VLDL + LDL fractions from diabetic patients. B iochem $\mathrm{M}$ ol Biol Int 32: 139- 147

22. A ustin M A , B reslow J L, H ennekens CH , B uring J E, Willet W C, K rauss R M (1988) Low density lipoprotein subclass patterns and risk of myocardial infarction. JAMA 13: 1917-1921

23. James RW, Pometta D (1990) Differences in lipoprotein subfraction composition and distribution between type 1 diabetic men and control subjects. D iabetes 39: 1158-1164

24. James RW, Pometta D (1991) The distribution profiles of very low density and low density lipoproteins in poorlycontrolled male, type 2 (non-insulin-dependent) diabetic patients. D iabetologia 34: 246-252

25. Feingold $K R$, G runfeld $C$, Pang $M$, D oerrler $W, K$ rauss R M (1992) LDL subclass phenotypes and triglyceride metabolism in non-insulin-dependent diabetes. A rteriosclerosis Thromb 12: 1496-1502

26. de G raaf J, H ak-L emmers H L M , H ectors M PC, D emacker PN M, H endriks JCM, Stalenhoef A FH (1991) Enhanced susceptibility to in vitro oxidation of the dense low density 
lipoprotein subfraction in healthy subjects. A rteriosclerosis 11: 298-306

27. A vogaro P, B ittolo B on G, Cazzolato G (1988) Presence of a modified low density lipoprotein in humans. A rteriosclerosis 8: 79-87

28. Cazzolato G, A vogaro P, Bittolo-B on G (1991) Characterization of an more electronegative charged LDL subfraction by ion exchange H PLC. Free Rad Biol M ed 11: 247253

29. Hodis HN, Kramsch DM, Avogaro P et al. (1994) Biochemical and citotoxic characteristics of an in vivo circulating oxidized low density lipoprotein (LDL-). J Lipid Res 35: 669-677

30. Shimano H, Yamada N, I shibashi S et al. (1991) O xidationlabile subfraction of human plasma low density lipoprotein isolated by ion-exchange chromatography. J Lipid Res 32: 763-773

31. D emuth K, M yara I, Chappey B, Vedie B, M oatti N (1995) Electronegative LDL subfraction isolated from human plasma by anion exchange FPLC is not an oxidized $L D L$ subfraction. A therosclerosis 115[Suppl]:S75 (A bstract)

32. Hodis N H , K ramsch D M , Sevanian A et al. (1991) Correlation between circulating modified low density lipoprotein and severity of atherosclerosis. Clin Res 39: 399A (A bstract)

33. National Diabetes Data G roup (1979) Classification and diagnosis of diabetes mellitus and other categories of glucose intolerance. D iabetes 28: 1039-1057

34. Lipid R esearch Clinic Program (1982) Manual of laboratory operations, lipid and lipoprotein analysis. In: $\mathrm{H}$ ainline A, Karon J, Lippel K (eds) ( $2^{\text {nd }}$ ) National, Heart, Lung and Blood Institute, Bethesda, MD (US Government Printing O ffice N o. 1982-361-132: 678). HEW Publication No. (NIH): 75-628 (revised)

35. B radford MA (1976) A rapid and sensitive method for the quantitation of microgram quantities of protein utilizing the principle of protein dye-binding. A nal Biochem 72: 248-254

36. Havel RJ, Eder HA, Bragdon JH (1955) The distribution and chemical composition of ultracentrifugally separated lipoproteins in human serum. J Clin Invest 34: 1345-1353

37. Vedie B, M yara I, Pech M A, M aziere J C, M aziere C, Caprani A, M oatti N (1991) Fractionation of charge-modified low density lipoprotein by fast protein liquid chromatography. J Lipid Res 32: 1359-1369

38. Sánchez-Q uesada J L, H oms-Serradesanferm R, SerratSerrat J, Serra-G rima JR, G onzález-Sastre F, O rdónmezLlanos J (1995) Increase of LD L susceptibility to oxidation occurring after intense, long duration aerobic exercise. A therosclerosis 118: 297-305

39. E sterbauer H, Striegl G, Puhl H, R othender M (1989) Continuous monitoring of in vitro oxidation of human low density lipoprotein. Free $R$ ad $R$ es Commun 6: 67-75

40. G riffin B A, Caslake M J , Y ip B, Tait G W, Packard CJ, Shepherd J (1990) Rapid isolation of low density lipoprotein subfractions from plasma by density gradient ultracentrifugation. A therosclerosis 83: 59-67

41. A ustin M A, K ing M C, V ranizan K M, Newman B, K rauss R M (1988) Inheritance of low-density subclass patterns: results of complex segregation analysis. A m J H um G enet 43: 838-846
42. K rauss $R M$, Burke DJ (1982) Identification of multiple LDL subclasses of plasma lipoproteins in normal humans. J Lipid Res 23: 97-103

43. L esnik P, Vonica A , G uerin M, M oreau M , Champman MJ (1993) A nticoagulant activity of tissue factor pathway inhibitor in human plasma is preferentially associated with dense subspecies of $L D L$ and HDL and with $L p(a)$. A rterioscl Thromb 13: 1066-1075

44. Jay Smith S, Cooper G R, M yers G L, Sampson EJ (1993) Biological variability in concentrations of serum lipids: sources of variation among results from published studies and composite predicted values. Clin Chem 39: 1012-1022

45. B agdade J D, H elve E, Taskinen M R (1991) E ffects of continuous insulin infusion therapy on lipoprotein surface and core lipid composition in insulin-dependent diabetes mellitus. M etabolism 40: 445-449

46. L eonhardt W, H anefeld M, M üller G et al. (1995) I mpact of concentration of glycosilated hemoglobin on the lag time of oxidizability of low density lipoproteins. A therosclerosis 115:S23 (A bstract)

47. Julier K, Dean J D, M ackness M I, Durrington PN (1995) Susceptibility of low and high density lipoproteins from subjects with diabetes to in vitro oxidative modification. A therosclerosis 115:S23 (A bstract)

48. Lyons TJ (1991) Oxidized low density lipoproteins: a role in the pathogenesis of atherosclerosis in diabetes? D iabetes Care 8: 411-419

49. B rownlee M, V lassara H, Cerami A (1985) N on-enzymatic glycosylation products on collagen covalently trap low density lipoprotein. D iabetes 34: 938-941

50. Walzem R L, Watkins S, Frankel E N, H ansen RJ, German JB (1995) Older plasma lipoproteins are more susceptible to oxidation: a linking mechanism for the lipid and oxidation theories of atherosclerotic cardiovascular disease. Proc N atl A cad Sci U SA 92: 7460-7464

51. Steinbrecher U P, Witztum J L (1984) G lucosylation of low density lipoproteins to an extent comparable to that seen in D iabetes slows their catabolism. 33: 130-134

52. M akino K, Furbee J W, Scanu A M, Fless G M (1995) E ffect of glycation on the properties of lipoprotein (a). A rterioscl Thomb Vasc Biol 15: 385-391

53. G ugluicci-Creriche A, Stahl A J C (1993) G lycation and oxidation of human low density lipoproteins reduces heparin binding and modifies charge. Scand J Clin L ab Invest 53: 125-132

54. Tertov V V, Sobenin IA, Tonevitsky A G, Orekhov A N, Smirnov V N (1990) I solation of atherogenic modified (desialylated) low density lipoprotein from blood of atherosclerotic patients: separation from native lipoprotein by affinity chromatography. Biochem Biophys Res Commun 167: 1122-1130

55. Winocour $P H, D$ urrington $P N, B$ hatnagar $D$, I shola $M, A r-$ rol S, M ackness M (1992) A bnormalities of VLDL, IDL and LD L characterize insulin-dependent diabetes mellitus. A rterioscler Thromb 12: 920-928

56. Parthasarathy S, Satanam N (1994) M echanisms of oxidation, antioxidants, and atherosclerosis. Curr O pin Lipidol 5: $371-375$

57. R uotolo G, Parlavecchia M, Taskinen M R, G alimberti G, Z oppo A , L e NA (1994) N ormalization of lipoprotein composition by intraperitoneal insulin in IDDM. Diabetes Care 17: 6-12 